INTERNATIONAL JOURNAL OF MULTIDISCIPLINARY RESEARCH AND ANALYSis

ISSN(print): 2643-9840, ISSN(online): 2643-9875

Volume 03 Issue 11 November 2020

DOI: 10.47191/ijmra/v3-i11-06, Impact Factor: 5.522

Page No.- 233-239

\title{
Study on the Growth Indices in Food Firms Listed on the Hanoi Stock Exchange
}

\author{
Luong Ngoc $\mathrm{Hieu}^{1}$, LeQuang Trung ${ }^{2}$ \\ ${ }^{1}$ Hanoi Metropolitan University, Vietnam \\ ${ }^{2}$ Faculty of Accounting, University of Labor and Social Affairs, Vietnam
}

\begin{abstract}
The study investigates growth indices of food firms listed in the Hanoi stock exchange (HNX). The study employs a set of aggregated data from 15 food firms listed on the HNX. At the same time, the study also receives comments from experts experienced in the research field. We have performed some descriptive analysis, compared with support by software Stata to evaluate and measure growth indices of food firms listed on the HNX. The results show that there is a big difference in growth indices of food firms listed on the HNX. Foreign ownership accounts for a relatively low proportion of these firms.
\end{abstract}

KEYWORDS: growth indices, finance, food firms

JEL CODES: F65, G32, 016

\section{INTRODUCTION}

Financial indicators are widely used when researching the financial situation of an enterprise (Osterryoung et al., 1992). The financial ratio is to determine the strengths and weaknesses of an enterprise as well as the important relationship between its resources and financial flows.

There is a direct influence of financial ratios on the business results and on growth of the enterprise. Managers and investors often use data analysis tools to track results, to know whether their efforts make a meaningful and significant difference.

Integrating intelligent analytical processes into corporate management activities and tracking financial ratios contribute to helping the Board of Directors of enterprises to make a right and timely decision related to the enterprise operation.

The growth indices in enterprises help analysts to identify other analytical tasks such as analysis methods and orders/processes, type of analysis, analysis reports.

This study analyzes, evaluates and measures growth indicators of food firms listed on the HNX, including: (i) Net revenue growth; (ii) Gross profit growth, (iii) Profit before tax growth, (iv) Growth of total assets.

\section{LITERATURE REVIEW}

Using financial indicators to analyze and forecast the financial situation of the enterprises as well as the firm performance has been concerned by numerous researchers around the world and in the country. Li \& Sun (2011), Bae (2012) forecasts financial difficulties under financial terms with the implication that the company has a negative cumulative profit, decreased dividend payments, loan agreement breaches, negative operational cash flow. Moradi et al (2012) affirmed that the lower the total asset turnover ratio of the company is, the higher the possibility of financial difficulty. Companies with a higher the ratio of debt management is more likely to overcome a financial hardship (Lin et al., 2014). The lower the ratio of return to total assets is, the higher the likelihood of experiencing a financial difficulty is (Lu \& Wang, 2010). The lower the ratio of profit after tax to revenue is, the higher the probability of financial hardship (Bea, 2012).

Vo and Thai (2016) affirmed that financial difficulties forecasting is an empirical research topic that has been of interest to many researchers and companies over the past few decades. The authors use the trend-based regression analysis method, choose the research scope as companies listed on the Ho Chi Minh City Stock Exchange in the period 2009-2014 to analyze and forecast financial difficulties through financial indicators. The research results show that financial indicators can be used for early warning of financial difficulties such as liquidity indices group, performance indicators group, debt repayment ratio group, group of profitability ratios and growth indices group including the sustainable growth rate, profit growth rate, growth rate of total assets and revenue growth rate. 


\section{Study on the Growth Indices in Food Firms Listed on the Hanoi Stock Exchange}

Nguyen and Nguyen (2017) analyze basic financial indicators of enterprises in the Commerce, Consulting, and Logistics sectors (industry group 5), including: payment index, firm performance index, financial leverage, profitability ratios, capital and revenue adequacy ratios. The authors conclude, the ideal health status of enterprises, from the perspective of financial indicators, is reflected through the system of optimal standards of indicators. A change in an index of a firm which is closer to the optimal standard of that indicator will be recorded as a better performance. Conversely, if there is any change in the opposite direction to the norm of optimization, the state is noted as a weaker performance.

Nguyen (2018) uses data from financial statements, clarifies the calculation of some financial indicators to evaluate the financial health of enterprises. The author analyzes a set of financial indicators that have the most impact on the financial health of a business, including: (i) Operational performance, (ii) liquidity and financial risks and (iii) market measurement.

Inheriting previous studies, this study uses a mixed research method to analyze the growth indices in food firms listed on the HNX through the evaluation four (4) ratios in the period 2015-2019, including: (i) Net revenue growth (NRG); (ii) Gross profit growth (GPG), (iii) Profit before tax growth (PBTG), (iv) Growth of total assets (GTA). The research results could contribute to analyzing the performance situation of enterprises and are meaningful for enterprise managers to make effective business decisions.

\section{METHODOLOGY}

The study uses balance sheet data, data collected by subjects and by time - series. The secondary data collected from the audited financial statements of 15 food firms listed in HNX in operation by the end of the accounting year 2019 on such reputable website https://finance.vietstock.vn/. Thus, this study has 15 firms $* 5$ years $=75$ observed variables, which have been processed and cleaned with excel, the remaining 74 observations were included in the analysis.

The research uses both qualitative and quantitative research methods. For the quantitative research method, the supporting tool is Stata13. This software allows us to analyze, evaluate and measure growth indices of the food firms listed on HNX.

\section{RESEARCH RESULTS AND DISCUSSION}

\subsection{Descriptive statistics results}

Table 1: General descriptive statistics of growth indices

\begin{tabular}{r|rrrrr} 
Variable & Obs & Mean & Std. Dev. & Min & Max \\
\hline RGR & 74 & .0526838 & .3950189 & -1 & 1.7864 \\
GPGR & 74 & .1188024 & .7564528 & -1.1341 & 4.0766 \\
IGR & 74 & -.0383598 & 3.00731 & -20.6828 & 9.8524 \\
AGR & 74 & .0445771 & .2896758 & -1 & 1.0962
\end{tabular}

\section{Sources: StataSofware 13}

Table 1 shows: There are 4 growth indicators, each of which is described by 74 observations (obs); basic indicators such as average value (mean), maximum value ( $\max$ ), minimum value $(\mathrm{min})$, standard deviation (sd) of each index have been identified and these basic indicators accurately reflect the current financial situation of food firms listed on the HNX.

Table 2: Foreign shareholders own more than $10 \%$ capital of food firms listed on the HNX

\begin{tabular}{r|rrr} 
CS & Freq. & Percent & Cum. \\
\hline 0 & 63 & 85.14 & 85.14 \\
1 & 11 & 14.86 & 100.00 \\
\hline Total & 74 & 100.00 &
\end{tabular}

Sources: StataSofware 13

Table 2: Descriptive statistics, comparison of ownership structure of food firms listed on HNX with the support of Stata13 software. The results of Table 2 show that, within 5 years, from 2015 to 2019, there were 11 enterprises (14.86\%) owned by major foreign shareholders with the share ownership rate more than $10 \%$. 
Study on the Growth Indices in Food Firms Listed on the Hanoi Stock Exchange

Table 3: Correlation analysis results

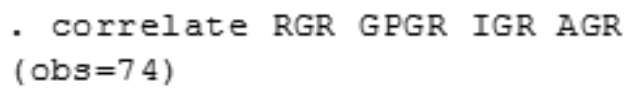

\begin{tabular}{r|rrrr} 
& RGR & GPGR & IGR & AGR \\
\hline RGR & 1.0000 & & & \\
GPGR & 0.3772 & 1.0000 & & \\
I GR & 0.1699 & 0.4792 & 1.0000 & \\
AGR & 0.1256 & 0.3003 & 0.1290 & 1.0000
\end{tabular}

Sources: StataSofware 13

Table 3 shows the results of correlation analysis, as known as multicollinearity analysis. The results indicate that the absolute value of each correlation coefficient between the two growth indices is less than 0.8 ; therefore, there is no multicollinearity phenomenon between the growth indicators.

\subsection{Net Revenue Growth}

Table 4: Net Revenue GrowthRatioof food firms listed on the HNX during the period 2015-2019

\begin{tabular}{|l|l|l|l|l|l|l|}
\hline Stock code & $\mathbf{2 0 1 5}$ & $\mathbf{2 0 1 6}$ & $\mathbf{2 0 1 7}$ & $\mathbf{2 0 1 8}$ & $\mathbf{2 0 1 9}$ & Average \\
\hline CAN & $6.48 \%$ & $-0.72 \%$ & $-2.96 \%$ & $14.64 \%$ & $20.60 \%$ & $7.89 \%$ \\
\hline CAP & $2.34 \%$ & $5.20 \%$ & $-15.63 \%$ & $42.68 \%$ & $-5.86 \%$ & $6.60 \%$ \\
\hline HAD & $0.14 \%$ & $-4.57 \%$ & $-13.45 \%$ & $-65.04 \%$ & $178.64 \%$ & $23.90 \%$ \\
\hline HAT & $9.26 \%$ & $10.48 \%$ & $0.90 \%$ & $20.93 \%$ & $13.92 \%$ & $11.56 \%$ \\
\hline HHC & $0.84 \%$ & $5.36 \%$ & $4.16 \%$ & $14.49 \%$ & $6.75 \%$ & $7.69 \%$ \\
\hline HKB & $-4.50 \%$ & $76.03 \%$ & $-81.84 \%$ & $-83.60 \%$ & $-91.61 \%$ & $-45.26 \%$ \\
\hline KTS & $53.49 \%$ & $-0.74 \%$ & $1.30 \%$ & $72.34 \%$ & $-34.36 \%$ & $9.64 \%$ \\
\hline MCF & $-43.40 \%$ & $-8.03 \%$ & $-12.91 \%$ & $48.71 \%$ & $-23.89 \%$ & $0.97 \%$ \\
\hline NST & $13.28 \%$ & $-2.17 \%$ & $-30.25 \%$ & $9.35 \%$ & $66.03 \%$ & $10.74 \%$ \\
\hline SAF & $10.61 \%$ & $18.97 \%$ & $6.08 \%$ & $8.62 \%$ & $5.16 \%$ & $9.71 \%$ \\
\hline SGC & $11.46 \%$ & $12.71 \%$ & $9.07 \%$ & $-0.10 \%$ & $10.54 \%$ & $8.06 \%$ \\
\hline SLS & $34.37 \%$ & $-100.00 \%$ & $0.00 \%$ & $11.80 \%$ & $46.10 \%$ & $-10.53 \%$ \\
\hline THB & $14.35 \%$ & $8.83 \%$ & $-0.23 \%$ & $4.92 \%$ & $91.51 \%$ & $26.26 \%$ \\
\hline VDL & $19.53 \%$ & $5.32 \%$ & $32.43 \%$ & $-21.74 \%$ & $-33.21 \%$ & $-4.30 \%$ \\
\hline VTL & $9.52 \%$ & $-4.32 \%$ & $-7.80 \%$ & $32.70 \%$ & $-20.15 \%$ & $0.11 \%$ \\
\hline
\end{tabular}

Sources: https://finance.vietstock.vn/and authors synthesized

Table 5: Average Net Revenue GrowthRatioover the years of food firms listed on the HNX

\begin{tabular}{|l|c|c|c|c|c|c|}
\hline Description & $\mathbf{2 0 1 5}$ & $\mathbf{2 0 1 6}$ & $\mathbf{2 0 1 7}$ & $\mathbf{2 0 1 8}$ & $\mathbf{2 0 1 9}$ & Average 2015-2019 \\
\hline Net Revenue Growth Ratio & $9.16 \%$ & $1.91 \%$ & $-7.95 \%$ & $5.57 \%$ & $17.88 \%$ & $5.31 \%$ \\
\hline
\end{tabular}

Sources: https://finance.vietstock.vn/and authors synthesized

Revenue Growth Ratio indicates relative growth in revenue (as a percentage) over time. A small proportion of this rate does not mean a negative growth.

Annual revenue growth measures the increase in a company's revenue for one year compared to the revenue of another year. Sales for the current year can be compared on the basis of two consecutive years (for example, the second year revenue is compared to the first year revenue).

Where revenue of any periods prior to the current period is zero, the revenue growth rate is indeterminate (usually only when the reporting period is quarterly, or during the first year in operation of the enterprise, or the company did not generate revenue in that period).

The formula for calculating revenue growth rate is as follows: (DTO-DTi) * $100 \%$ / DTi 


\section{Study on the Growth Indices in Food Firms Listed on the Hanoi Stock Exchange}

In which, DTO is the current period revenue. DTi is the revenue of i previous period (s). A period can be the last 4 quarters, the most recent 1 year, the last 3 years or the last 5 years. One period in this study is the most recent 1 year. Revenue can also be replaced by net revenue if net revenue growth calculation is required. Negative sales may appear in quarterly business reports (in the event that goods from the previous quarter are returned), but are not allowed to be presented in annual business reports.

Enterprises with high revenue growth rate are often in a strong growth phase, which the market shares are increasing, or enterprises are expanding their business into new markets or fields. However, a high revenue growth rate is not necessarily associated with high profit growth. Depending on the trend of the revenue growth rate, the growth rate is considered to be sustainable, unstable, galloping or sloping down.

Revenue growth helps analysts, investors and other stakeholders follow how much a company's revenue has increased over time.

When reviewing a company's quarterly or annual financial position, it's not enough just to look at the current period. When investing in a company, the investor wants to see its growth or improvement over time.

Comparing a company's financial data from period to period indicates the company's revenue growth and helps investors identify drivers of that growth.

Table 4 shows that: 3 enterprises with stock codes HAT, HHC, SAF had continuous positive Net revenue growth index in the period 2015-2019. Two enterprises with stock codes HAD and THB had the highest average net revenue growth index in the period 2015-2019 in light of the significant increase in revenue growth in 2019 of these two enterprises.

Table 5 shows that: The average net revenue growth over years of food firms listed on the HNX fluctuated quite strongly. While the growth rate was negative in 2017, 2019 experienced the highest growth rate.

\subsection{Gross profit growth and Profit before tax growth}

Table 6: Gross profit growth ratio of food firms listed on the HNX during the period 2015-2019

\begin{tabular}{|c|c|c|c|c|c|c|}
\hline Stock code & $\mathbf{2 0 1 5}$ & $\mathbf{2 0 1 6}$ & $\mathbf{2 0 1 7}$ & $\mathbf{2 0 1 8}$ & $\mathbf{2 0 1 9}$ & Average \\
\hline CAN & $-5.94 \%$ & $-18.44 \%$ & $2.42 \%$ & $20.55 \%$ & $22.75 \%$ & $4.27 \%$ \\
\hline CAP & $11.13 \%$ & $-15.39 \%$ & $-8.65 \%$ & $48.17 \%$ & $-1.68 \%$ & $6.72 \%$ \\
\hline HAD & $11.37 \%$ & $-12.38 \%$ & $-9.03 \%$ & $-5.12 \%$ & $5.13 \%$ & $-2.01 \%$ \\
\hline HAT & $2.53 \%$ & $-45.98 \%$ & $40.41 \%$ & $1.11 \%$ & $-15.38 \%$ & $-3.46 \%$ \\
\hline HHC & $5.07 \%$ & $1.59 \%$ & $23.01 \%$ & $33.40 \%$ & $-0.55 \%$ & $12.50 \%$ \\
\hline HKB & $-61.26 \%$ & $407.66 \%$ & $-113.41 \%$ & $112.80 \%$ & $-58.65 \%$ & $57.43 \%$ \\
\hline KTS & $372.77 \%$ & $29.75 \%$ & $4.25 \%$ & $-63.55 \%$ & $-12.03 \%$ & $66.24 \%$ \\
\hline MCF & $-29.04 \%$ & $-0.43 \%$ & $-14.78 \%$ & $21.37 \%$ & $-2.70 \%$ & $-5.12 \%$ \\
\hline NST & $-0.90 \%$ & $-30.24 \%$ & $21.43 \%$ & $9.44 \%$ & $35.58 \%$ & $7.06 \%$ \\
\hline SAF & $-5.40 \%$ & $15.26 \%$ & $16.44 \%$ & $21.21 \%$ & $0.64 \%$ & $9.63 \%$ \\
\hline SGC & $27.93 \%$ & $31.34 \%$ & $2.89 \%$ & $-15.23 \%$ & $30.16 \%$ & $15.42 \%$ \\
\hline SLS & $164.98 \%$ & $-100.00 \%$ & $0.00 \%$ & $-19.87 \%$ & $-24.72 \%$ & $5.10 \%$ \\
\hline THB & $-28.10 \%$ & $28.20 \%$ & $2.88 \%$ & $5.01 \%$ & $49.90 \%$ & $11.58 \%$ \\
\hline VDL & $-20.17 \%$ & $-34.90 \%$ & $4.81 \%$ & $-31.93 \%$ & $7.85 \%$ & $-14.87 \%$ \\
\hline VTL & $-5.45 \%$ & $4.65 \%$ & $-10.71 \%$ & $123.34 \%$ & $-80.03 \%$ & $6.36 \%$ \\
\hline
\end{tabular}

Sources: https://finance.vietstock.vn/and authors synthesized

Table 7: Average Gross profit growthratio over the years of food firms listed on the HNX

\begin{tabular}{|l|l|l|l|l|l|l|}
\hline Description & $\mathbf{2 0 1 5}$ & $\mathbf{2 0 1 6}$ & $\mathbf{2 0 1 7}$ & $\mathbf{2 0 1 8}$ & $\mathbf{2 0 1 9}$ & Average 2015-2019 \\
\hline Gross profit growthratio & $29.3 \%$ & $17.38 \%$ & $-2.72 \%$ & $17.38 \%$ & $-2.92 \%$ & $31.65 \%$ \\
\hline
\end{tabular}

Sources: https://finance.vietstock.vn/and authors synthesized

Table 8: Profit before tax growthratio of food firms listed on the HNXduring the period 2015-2019

\begin{tabular}{|l|c|c|c|c|c|c|}
\hline Stock code & $\mathbf{2 0 1 5}$ & $\mathbf{2 0 1 6}$ & $\mathbf{2 0 1 7}$ & $\mathbf{2 0 1 8}$ & $\mathbf{2 0 1 9}$ & Average \\
\hline CAN & $-19.84 \%$ & $-92.48 \%$ & $400,56 \%$ & $-112.15 \%$ & $-2,068.28 \%$ & $-378.44 \%$ \\
\hline CAP & $73.68 \%$ & $-40.57 \%$ & $9.53 \%$ & $66.62 \%$ & $-12.62 \%$ & $19.33 \%$ \\
\hline HAD & $-7.18 \%$ & $-21.95 \%$ & $-22.27 \%$ & $-22.30 \%$ & $-3.69 \%$ & $-15.48 \%$ \\
\hline
\end{tabular}


Study on the Growth Indices in Food Firms Listed on the Hanoi Stock Exchange

\begin{tabular}{|l|c|c|c|c|c|c|}
\hline HAT & $-75.68 \%$ & $159.75 \%$ & $77.95 \%$ & $5.54 \%$ & $-44.58 \%$ & $24.60 \%$ \\
\hline HHC & $0.41 \%$ & $22.76 \%$ & $0.76 \%$ & $25.93 \%$ & $-3.33 \%$ & $9.31 \%$ \\
\hline HKB & $-72.25 \%$ & $985.24 \%$ & $-190.36 \%$ & $-211.76 \%$ & $101.32 \%$ & $122.44 \%$ \\
\hline KTS & $807.45 \%$ & $80.48 \%$ & $4.80 \%$ & $-76.61 \%$ & $-52.68 \%$ & $152.69 \%$ \\
\hline MCF & $-37.55 \%$ & $4.29 \%$ & $-22.52 \%$ & $0.97 \%$ & $2.38 \%$ & $-10.49 \%$ \\
\hline NST & $-242.75 \%$ & $-160.01 \%$ & $6.64 \%$ & $4.46 \%$ & $10.68 \%$ & $-76.20 \%$ \\
\hline SAF & $10.73 \%$ & $9.74 \%$ & $9.93 \%$ & $22.44 \%$ & $4.31 \%$ & $11.43 \%$ \\
\hline SGC & $32.51 \%$ & $34.39 \%$ & $4.93 \%$ & $-23.13 \%$ & $42.08 \%$ & $18.16 \%$ \\
\hline SLS & $243.17 \%$ & $-100.00 \%$ & $0 \%$ & $-29.16 \%$ & $-45.45 \%$ & $17.14 \%$ \\
\hline THB & $-58.48 \%$ & $-21.98 \%$ & $-13.35 \%$ & $-39.91 \%$ & $167.07 \%$ & $6.67 \%$ \\
\hline VDL & $23.47 \%$ & $-17.06 \%$ & $1.99 \%$ & $-15.57 \%$ & $-6.50 \%$ & $-2.73 \%$ \\
\hline VTL & $47.68 \%$ & $5.85 \%$ & $4.84 \%$ & $353.42 \%$ & $-170.62 \%$ & $48.23 \%$ \\
\hline
\end{tabular}

Sources: https://finance.vietstock.vn/and authors synthesized

Table 9: Average Profit before tax growthratio over the years of food firms listed on the HNX

\begin{tabular}{|l|c|c|c|c|c|c|}
\hline Description & $\mathbf{2 0 1 5}$ & $\mathbf{2 0 1 6}$ & $\mathbf{2 0 1 7}$ & $\mathbf{2 0 1 8}$ & $\mathbf{2 0 1 9}$ & Average 2015-2019 \\
\hline Profit before tax growth ratio & $48.36 \%$ & $56.56 \%$ & $19.53 \%$ & $-3.41 \%$ & $-138.66 \%$ & $-3.52 \%$ \\
\hline
\end{tabular}

Sources: https://finance.vietstock.vn/and authors synthesized

Income Growth Rate indicates relative growth in profit (in percent) over time. A small ratio does not implicate a negative growth. Where the profit of any periods prior to the current period is zero, the rate of profit growth is indeterminate.

The formula for calculating the profit growth rate is as follows:

Income growth $n$ periods

$\frac{\mathrm{LN}_{0}-\mathrm{LN}_{1}}{\left|\mathrm{LN}_{1}\right|}+\ldots+\frac{\mathrm{LN}_{\mathrm{n}-1}-\mathrm{LN}_{\mathrm{n}}}{\left|\mathrm{LN}_{\mathrm{n}}\right|}$

Source: quantri.vn

In which LNO is profit of the current period. LNn is the profit of $\mathrm{n}$ previous periods. A period can be the last 4 quarters, the most recent 1 year, the last 3 years or the last 5 years. In this study, a period is the most recent 1 year.

Depending on needs in each case, we can use gross profit or net profit from operating activities, use total profit before or after tax to calculate the growth rate of different types of profits. Many financial analysts have not analyzed indicators related to profit after tax because of its complexity. In order to calculate the profit after tax, it is necessary to calculate and review a reasonable and valid expense, taxable turnover and income; corporate income tax expenses and corporate income tax rate.

If only a short period of time is reviewed, the rate of profit growth can suddenly increase or decrease for many reasons, such as assets liquidating or provisioning. Therefore, when analyzing corporate finance, it is necessary to consider the growth rate over a long enough period, at the same time it is also important to consider whether the profit growth of the business is sustainable.

Depending on the trend of profit growth rates, the growth rate is considered to be sustainable, unstable, galloping or sloping down. Enterprises with stably high profit growth always specially attract investors' attention.

Table 8 presents that enterprise with stock code SAF had a positive and stable growth rate of profit in the period 2015-2019. The enterprise with securities code KTS had the highest average profit growth rate for the period 2015-2019. Meanwhile, the enterprise code CAN had the lowest average profit growth rate during 2015-2019.

Table 9 shows that the average Profit before tax growth in the period 2015-2019 of the food firms listed on the HNX was -3.52\%. In which, year 2018 and 201 experienced a negative rate.

\subsection{Growth of total assets}

Table 10: Growth of total assetsratio of food firms listed on the HNX during the period 2015-2019

\begin{tabular}{|l|c|c|c|c|c|c|}
\hline Stock code & $\mathbf{2 0 1 5}$ & $\mathbf{2 0 1 6}$ & $\mathbf{2 0 1 7}$ & $\mathbf{2 0 1 8}$ & $\mathbf{2 0 1 9}$ & Average \\
\hline CAN & $19.32 \%$ & $-4.72 \%$ & $-1.33 \%$ & $10.07 \%$ & $21.09 \%$ & $8.89 \%$ \\
\hline CAP & $6.05 \%$ & $-5.20 \%$ & $13.38 \%$ & $0.30 \%$ & $-3.39 \%$ & $2.23 \%$ \\
\hline HAD & $4.19 \%$ & $0.35 \%$ & $-8.37 \%$ & $37.06 \%$ & $-5.51 \%$ & $5.54 \%$ \\
\hline
\end{tabular}


Study on the Growth Indices in Food Firms Listed on the Hanoi Stock Exchange

\begin{tabular}{|l|c|c|c|c|c|c|}
\hline HAT & $27.65 \%$ & $-3.54 \%$ & $-14.73 \%$ & $17.34 \%$ & $-9.79 \%$ & $3.39 \%$ \\
\hline HHC & $14.00 \%$ & $30.44 \%$ & $1.83 \%$ & $98.23 \%$ & $13.63 \%$ & $31.63 \%$ \\
\hline HKB & $49.21 \%$ & $109.62 \%$ & $-11.23 \%$ & $-23.44 \%$ & $-8.52 \%$ & $23.13 \%$ \\
\hline KTS & $10.28 \%$ & $-4.60 \%$ & $9.12 \%$ & $-14.74 \%$ & $-81.39 \%$ & $-16.27 \%$ \\
\hline MCF & $-20.80 \%$ & $8.71 \%$ & $-11.66 \%$ & $17.57 \%$ & $3.42 \%$ & $-0.55 \%$ \\
\hline NST & $9.09 \%$ & $-17.78 \%$ & $-8.65 \%$ & $-11.06 \%$ & $31.82 \%$ & $0.68 \%$ \\
\hline SAF & $-4.01 \%$ & $19.80 \%$ & $0.13 \%$ & $19.09 \%$ & $6.90 \%$ & $8.38 \%$ \\
\hline SGC & $12.77 \%$ & $16.49 \%$ & $-3.72 \%$ & $0.89 \%$ & $9.18 \%$ & $7.12 \%$ \\
\hline SLS & $8.04 \%$ & $54.94 \%$ & $0 \%$ & $-7.39 \%$ & $-13.37 \%$ & $10.56 \%$ \\
\hline THB & $-3.30 \%$ & $-4.62 \%$ & $-5.59 \%$ & $5.97 \%$ & $-14.52 \%$ & $-4.41 \%$ \\
\hline VDL & $17.30 \%$ & $7.91 \%$ & $13.35 \%$ & $-12.49 \%$ & $15.90 \%$ & $8.39 \%$ \\
\hline VTL & $15.01 \%$ & $-34.77 \%$ & $60.15 \%$ & $-43.50 \%$ & $-100.00 \%$ & $-20.62 \%$ \\
\hline
\end{tabular}

Sources: https://finance.vietstock.vn/and authors synthesized

Table 11: Average Growth of total assetsratio over the years of food firms listed on the HNX

\begin{tabular}{|l|c|c|c|c|c|c|}
\hline Description & $\mathbf{2 0 1 5}$ & $\mathbf{2 0 1 6}$ & $\mathbf{2 0 1 7}$ & $\mathbf{2 0 1 8}$ & $\mathbf{2 0 1 9}$ & Average 2015-2019 \\
\hline Growth of total assets ratio & $10.99 \%$ & $11.54 \%$ & $2.33 \%$ & $6.26 \%$ & $-8.97 \%$ & $4.43 \%$ \\
\hline
\end{tabular}

Sources: https://finance.vietstock.vn/and authors synthesized

Growth of total assets ratiorefers to the relative growth in asset (in percent) over time. A negative asset growth ratio implicates a negative growth. In the case assets of any periods prior to the current period is zero, the rate of assets growth is indeterminate.

The formula for calculating Growth of total assets rate is as follows:

Growth of total assets ratio n periods $^{\prime}=\frac{\frac{\mathrm{TS}_{0}-\mathrm{TS}_{1}}{\left|\mathrm{TS}_{1}\right|}+\ldots+\frac{\mathrm{TS}_{\mathrm{n}-1}-\mathrm{TS}_{\mathrm{n}}}{\left|\mathrm{TS}_{\mathrm{n}}\right|}}{\mathrm{N}}$

\section{Source: quantri.vn}

Where TSO is the total assets of the current period,TSn is total assets of the $\mathrm{n}$ previous periods. A period can be the last 4 quarters, the most recent 1 year, the last 3 years or the last 5 years. In this study, a period is the most recent 1 year. Depending on each case, total assets, liquid assets, long-term assets, or fixed assets can be used to calculate the growth rates of different types of assets.

An increased asset growth does not ensure that enterprise is doing well. When analyzing the Growth of total assets rate, analysts should pay attention to several different factors: the purpose of asset growth, kind of asset that has been grown, sources of funding, etc.

If a firm uses undistributed profits to reinvest, an asset growth often means that the firm wants to expand its production, and this asset growth is often a good sign.

In the case the enterprise mainly uses capital from loans, analysts should be cautious when analyzing. Since the enterprise will have to pay both interest and principal for loan settlements, using loans to invest carries many risks, and wrong investment decisions can lead to heavy losses or bankruptcy (quantri.vn).

Concerns about asset growth rates vary widely across different industries. For example, with the banking industry, asset growth is one of the most important goals (besides credit growth), but this might not completely true for other industries.

Table 10 shows that the enterprise with stock code $\mathrm{HHC}$ had a positive Growth of total assets rate continuously from 2015 to 2019. An enterprise with stock code HKB had a negative Growth of total assets rate in 3 years 2017, 2018 , and 2019.

Table 11 presents that, in the period 2015-2019, the average Growth of total assets rate over the years of foodfirms listed on the HNX fluctuated widely. In 2019, the average total assets growth rate was negative.

\section{CONCLUSION}

This study has evaluated and measured 4 growth indices in food firms listed on the HNX with mixed research methors.

Enterprises with stable and high revenue growth are always paid special attention by investors.

Firms with high income growth rate are usually doing very well. 


\section{Study on the Growth Indices in Food Firms Listed on the Hanoi Stock Exchange}

It is impossible to conclude that enterprises do well when they have high and continuous asset growth.

\section{REFERENCES}

1) Bae, J. K. (2012). Predicting financial distress of the South Korean manufacturing industries. Expert Systems with Applications, 39(10):9159-9165. DOI: 10.1016/j.eswa.2012.02.058

2) Li, H., \& Sun, J. (2011). Predicting business failure using support vector machines with straightforward wrapper: A resampling study. Expert Systems with Applications: An International Journal, 38(10), 12747-12756.

3) Lin, F., Liang, D., Yeh, C. C., Huangc, J. C. (2014). Novel feature selection methods to financial distress prediction.Expert Systems with Applications, 41(5), 2472-2483.https://doi.org/10.1016/j.eswa.2013.09.047

4) Lu, Y., \& Wang, W. (2010). Financial Distress Prediction of Chinese Listed Companies Based on Panel Logit Model.2010 International Conference on Management and Service Science. DOI: 10.1109/ICMSS.2010.5578203.

5) Moradi, M., Sardasht, M. S., Ebrahimport, M. (2012). An application of support vector machines in Bankruptcy prediction: Evidence from Iran. World applied sciences Journal, 17(6), 710-717.

6) Nguyen, M. Q., \& Nguyen, P. T. (2017). Overview of industries through financial capacity index - services, tourism, hotel, book and school equipment sectors. The journal of Accounting \& Auditing, 10, 13-17. [Vietnamese]

7) Nguyen, T. T. (2018). The method of interpreting financial statements - The core set of indicators analyzes financial strength. Industry and trade magazine, 10, 332-337. [Vietnamese]

8) Osteryoung, J., Constand, R. L., Nast, D. (1992). Financial Ratios in Large Public and Small Private Firms.Journal of Small Business Management, 30 (3), 35-47

9) Vo, X. V., \& Thai, T. T. N. (2016).Forecast of financial difficulties by financial indicators using trend regression model research on Vietnam stock market. Banking Science \& Training Review, 164+165, 103-111. [Vietnamese]

10) Web: https://finance.vietstock.vn/; quantri.vn 